\title{
Editorial
}

\section{Preserving soil and crop resources by increasing cropping intensity and decreasing tillage}

Soils perform many essential functions for plant growth, water storage, and water and air quality. Future generations depend on our crop and soil management practices to maintain or improve the soil's ability to perform these essential functions while providing the food and fiber needed by society. Unfortunately, many soils have been degraded $^{1}$ because we either did not understand the negative effects of certain management practices or we lacked better alternatives. In recent years, scientific research, farmer innovation, and new commercial technologies have allowed improved soil management in many regions. In spite of this progress, additional improvements in soil management will be required to restore and then maintain the functional capacity of the soil resource.

The Great Plains of Canada and the US is a major agricultural region producing sorghum, corn, wheat, and other small grains. This productive region is also highly susceptible to the vagaries of climate and destructive natural forces, such as those that gave rise to the Dust Bowl in the 1930s. The continental climate of the Great Plains and western Corn Belt is characterized by highly variable precipitation and temperature, both within and among years.

Farmers who settled in this region, utilizing practices developed in more humid regions, experienced a high incidence of crop failure. In order to survive in the harsh, erratic environment of the Great Plains, different management practices were needed. Crop-fallow was developed as a practice to reduce the risk of crop failure due to water stress by allowing soil water to accumulate during the fallow period for use by the subsequent crop. Crop-fallow, using intensive tillage for seedbed preparation and weed control, soon became the dominant practice throughout the region. While the incidence of crop failure declined, the loss of organic matter, susceptibility of soil to wind and water erosion during the fallow period, development of extensive saline seeps, and the need for two growing seasons to produce a crop led many to conclude that cropfallow was not a sustainable system. As herbicides and minimum tillage implements became available, research was initiated throughout the region to develop more intensive cropping systems that kept the land under crops every year. Initial results from these studies demonstrated that annual yields and economic returns were greater with more intensive cropping ${ }^{2}$. In addition, wind erosion was reduced and precipitation use efficiency increased ${ }^{3}$. The impact of more intensive cropping on the soil resource was difficult to assess as changes in many soil properties occur slowly.

In the late 1970s, the concept of soil quality was introduced $^{4}$. Scientists have developed the soil quality concept into a tool useful in educating people about the relationships between soil properties and the essential functions performed by soils ${ }^{5}$. Soil quality has also developed into a useful concept for land managers to assess their progress toward managing their soils in a suitable manner. Soil quality assessments involve standardized measurement of soil properties that serve as indicators of important soil functions. These soil quality indicators can be used to compare alternative management practices or to monitor changes over time. Efforts are continuing to develop measurement protocols and interpretation tools that land managers and consultants can more easily use.

This special issue includes seven papers that focus on alternative cropping systems in the North American Great Plains. Five of these papers present results from a multilocation, long-term study aimed at improving the soil quality concept as a tool for assessing management and at identifying management practices that help maintain or improve soil functions. The sixth and seventh papers evaluate the energy use efficiency and profitability of alternative reduced tillage cropping systems. They suggest that the adoption of alternative soil management practices is largely governed by profitability considerations, which in turn, are likely to be influenced by both energy costs and government programs.

The soil quality studies used existing long-term cropping system experiments with well-defined treatment histories. Many of these long-term experiments were established by 
scientists who documented the detrimental effects of fallow on the soil resource and developed the more intensive cropping systems now common in the Great Plains. These experiments were designed to reduce the incidence of fallow, introduce crop rotations to break weed and disease cycles, and reduce tillage to maintain crop residue as a protective layer on the soil surface. These well-managed long-term studies provided the type of data needed to evaluate rigorously a number of recently developed analytical methods and assessment tools. The goal of the study reported in this series of papers is to identify soil properties that influence important soil functions, and evaluate accessible methods for measuring those properties. Many of the measured properties were used to evaluate two recently developed assessment tools. The soil properties identified, the methods validated, and the assessment tools tested will be useful for comparing future developments in soil management practices.

This series of papers also provides some important perspectives on how the timing and method of soil sampling can influence the interrelation of soil quality information. Careful documentation of sampling depth and measurement of bulk density is essential for understanding the temporal dynamics exhibited by many soil properties. It is only after the temporal dynamics are understood that management effects can be assessed.

Conditions in agriculture have changed a great deal since cropping began in the Great Plains. Crop-fallow was practiced for several decades with the dominant crop being wheat. As more intensive cropping systems were developed, additional crops were grown in rotation to break weed and disease cycles. Today, farmers readily alter their cropping practices in response to weather patterns, market pressures, and development of new technologies. Since many soil properties respond slowly to changes in management practices, it will be difficult to assess changes in these soil properties in a dynamic management system. It is hoped that the efforts reported in this special issue will contribute toward identifying methods and assessment tools useful for evaluating the sustainability of management systems as they evolve in the future. The review of the book
Managing Soil Quality - Challenges in Modern Agriculture is a fitting conclusion for this special issue and stresses the importance of management-based thresholds as tools for soil protection, physical and biological integrity, and managing soil quality.

The relationship between energy costs, enterprise profitability and adoption of soil quality-building cropping practices discussed in this issue reminds us of the need to integrate environmental costs and values of ecological services $^{6}$ into future research on soil quality impacts, energy use and profitability of alternative cropping systems.

\section{References}

1 Oldeman, L.R. 1994. The global extent of soil degradation. In D.J. Greenland and I. Szabolcs (eds). Soil Resilience and Sustainable Land Use. CAB International, Wallingford, UK. p. 99-118.

2 Dhuyvetter, K.C., Thompson, C.R., Norwood, C.A., and Halvorson, A.D.. 1996. Economics of dryland cropping systems in the Great Plains. Journal of Production Agriculture 9:216-222.

3 Peterson, G.A., Schlegel, A.J., Tanaka, D.L., and Jones, O.R. 1996. Precipitation use efficiency as affected by cropping and tillage systems. Journal of Production Agriculture 9:180-186.

4 Alexander, M. 1971. Agriculture's responsibility in establishing soil quality criteria. In Environmental Improvement Agriculture's Challenge in the Seventies. National Academy of Sciences, Washington, DC. p. 66-71.

5 Wienhold, B.J., Andrews, S.S., and Karlen, D.L. 2004. Soil quality: a review of the science and experiences in the USA. Environmental Geochemistry and Health 26:89-95.

6 Costanza, R., D'arge, R., De Groot, R., Farber, S., Grasso, M., Hannon, B., Limburg, K., Naeem, S., O’Neill, R.V., Paruelo, J., Raskin, R.G., Sutton, P., and Van Den Belt, M. 1997. The value of the world's ecosystem services and natural capital. Nature 387:253-260.

Brian J. Wienhold ${ }^{1} *$ and Ray R. Weil ${ }^{2}$

${ }^{1}$ USDA-ARS, Lincoln, NE 68583, USA.

${ }^{2}$ University of Maryland, College Park, MD 20742, USA.

*Corresponding author: bwienhold1@unl.edu 